\title{
Mental Health Street Triage: Comparing Experiences of Delivery across Three
}

\section{Sites}

\begin{abstract}
Introduction: The limited evidence on MHST is largely focused on service development and is overly police-centric dominated by narratives of risk. This article considers the interplay between officers and CPNs in practice situated within strategic and operational contexts, illustrating the importance of place to service developments and trust within practice.
\end{abstract}

Aim: This study was conducted to compare the processes, experiences, and perceptions of MHST in 3 sites in England.

Method: Semi-structured interviews were completed with 27 police and health service staff in strategic and operational roles over a three-month period in three sites in England.

Results: Four themes were identified: 'Reducing and improving the use of mental health detainments'; 'Importance of local contexts and partnerships', 'Enhancing officer confidence'; and 'Developing street triage'.

Discussion: MHST decision-making and outcomes were influenced by issues of trust, belonging and legitimacy within the interplay between officers and nurses. Continuity and staff turnover influenced strategic and operational development. However, MHST was perceived to be an effective and costsaving model.

Implications for practice: Mental health nurses are well positioned to lead awareness and education of officers in relation to mental health crisis response. Staff need to develop communication strategies that extend beyond those immediately involved in MHST. 
Keywords: Mental Health, Street Triage, Police, Community Psychiatric Nurse, Collaboration, Section 136

\section{Accessible Summary}

\section{What is already known about the topic}

- MHST represents transformation at the forefront of policing and mental health to people in crisis with the aim of providing a better and more efficient response.

- Current knowledge has largely focused on service development, informed by narratives of risk, and this study applies an alternative focus by considering the interplay in practice.

\section{What the paper adds to existing knowledge}

- This paper adds to emerging work on mental health street triage, offering original insights into the interplay of police officers and mental health nurses in practice.

- The evidence presented shows how the dynamics between officers and nurses were informed by perceptions of trust, belonging and legitimacy which shaped decision-making and outcomes.

- This study also reveals the impacts of leadership continuity and staff turnover to service efficacy and the potential of strategic 'drift'.

\section{What are the implications for practice}

- Nurses who work in MHST operations should be prepared to share knowledge, learning and insight into how different mental health conditions present in practice and support the assessment of risk posed to officers. 
- Alternative pathways available to detainment by police under the Mental Health Act should be identified and communicated to officers, both in the control room and in situ, to avoid unnecessary detentions.

- Strategies should be developed to extend the communication of mental health education and knowledge beyond those immediately involved in MHST to support the police to better respond to mental health.

\section{Relevance Statement}

This article focuses on mental health street triage operations, involving partnership between police and mental health services. Such operations are at the forefront of the response to an increasing mental health crisis demand on public services. Mental health nurses are central to the street triage and the findings of the study demonstrate how issues of trust between nurses and police officers impact shared ownership of decision-making and care planning. The article contributes to an important evidence-base around partnership working between police and health services, highlighting implications for the future shape of street triage in England and Wales.

\section{Introduction}

One in four people experience mental ill health every year (Kane et al., 2017) and one in ten will encounter the police on their pathway to mental health services (Livingston, 2016). A study in Quebec found that for offences of equal severity, a person with mental ill health is twice as likely to be arrested (Charrette et al., 2014). However, other studies have conversely found that the presence of mental illness reduces the chance of arrest (Engel \& Silver, 2001). In spite of these varied findings, much of the literature on this subject suggests that people with mental illnesses are disproportionately represented in the criminal justice system. The extent of increased risk for individuals suffering from mental ill health most likely varies based on jurisdiction, which leads to unequal criminalisation and, in the UK, inconsistent use of Section 136 (s136) powers of detainment 
(Home Office, 2014; Pettitt et al., 2013; Lamb et al., 2002). The last decade has seen a significant shift in the scrutiny of police and criminal justice system treatment of individuals with mental ill health, following The Bradley Report (2009) and further reviews of legislation, policy and practice (DoH, 2009; MoJ, 2011). Questions have been raised about the use of police cells as places of safety (O'Brien et al., 2017); provisions of mental health training for police officers (Cummins \& Edmondson, 2016); the appropriateness of police officers making decisions about an individual's mental health (Wood et al., 2011); the efficacy and timeliness of information sharing between agencies (Watson et al., 2010); levels of resources allocated (Cummins \& Edmondson, 2016), and; the extent of collaborative decision-making and shared goals between agencies ( $\mathrm{O}^{\prime}$ Brien et al., 2017). Recent legislative and policy changes have attempted to address such concerns, for example the introduction of the Mental Health Crisis Care Concordat and amendments to the Mental Health Act (1983) to protect individuals in mental health distress and ensure a more dignified process (DoH \& Concordat signatories, 2014; Policing and Crime Act, 2017).

It has been estimated that demand created by incidents involving an element of mental health account for up to $40 \%$ of police calls, with submissions from the Metropolitan Police and Kent Police to the House of Commons Home Affairs Committee on Policing for the Future (2018) placing the figure at $40 \%$ and $33 \%$ respectively. That said, the reliability of recording procedures brings these figures into question due to a lack of clarity around how calls into police control rooms are classified. It is, however, recognised that critical levels of demand are being created by mental health, leading to questions around the appropriateness of police being involved in mental health work (Winsor, 2017). Such debates are ongoing in local and national political and policy spheres, however, the development of MHST positions policing at the forefront of the response to individuals in crisis alongside health services as part of their duty to protect people from harm (HMICFRS, 2018).

'Mental health street triage' (MHST) has been adopted by some policing and health services to improve the response to individuals in mental health crisis (Cummins \& Edmondson, 2016). Existing 
international models broadly involve the coordinated collaboration of police and health services to improve information-sharing, decision-making and the experience for individuals presenting to police in mental health distress (Wood et al., 2011; Huppert \& Griffiths, 2015). This leads to expedited access to mental health services, reductions in the use of police cells as a 'place of safety' and reductions in repeat detainments (Horspool et al., 2016; Home Office, 2016). MHST emerged in 2013 when the UK Home Office funded 9 pilots, and the national evaluation found that all but two pilots reduced use of detainment powers under section 136 of the Mental Health Act (1983) and increased the use of health-based places of safety alongside a decrease in the average length of detainment (Home Office, 2016). The effective reduction in detainments is, however, not valid for all forces, as Keown et al. (2016) found that although the Northumbria Police MHST operation reduced the use of detainments by $56 \%$ over the course of a year, the proportion of those who met the threshold for mental health treatment did not significantly change. Therefore, whilst the overall volume of cases reduced, the ability of officers to identify a level of mental health need above the recognised threshold for treatment did not improve. As such, it is unclear whether MHST had improved practice in the local area which causally reduced demand or whether the demand had reduced unattributed to MHST.

The frequency of detainments has been, and continues to be, used by some as a proxy measure for effectiveness, which is highly debatable. To solely use this metric in determining success is reductive and oversimplifies the complexities of addressing mental health demand. Lady Hale (2017) argues that when judged in the context of the range of powers police officers can exercise, s136 might in fact be under-used. A key theme discussed in this paper relates to reducing and improving the use of these powers, following which, the discussion reflects on the role and value of policing in this arena.

MHST is now being implemented locally in many police force areas across England and Wales (Horspool et al., 2016), though local delivery models vary between deployable assets of nurses and 
officers attending incidents to assess an individual's mental health (Bhardwa, 2013), force control room-based nurses providing remote advice to response officers at the scene of an incident (Home Office, 2016), and a hybrid approach (Callender \& Cole, 2016). Resources dedicated to MHST differ considerably, with some forces committing up to three response vehicles (Baraki et al., 2017), and others only one (Reveruzzi \& Pilling, 2016). Further differences include the relative commitment of police officers to the operation, whereby in some areas there is a permanent team dedicated to MHST and in other areas a response officer is assigned at random to support the nurse on duty (Reveruzzi \& Pilling, 2016). The most fruitful model was suggested to be a combined approach, which includes a joint response vehicle and a mental health nurse in a control room (Horspool et al., 2016).

Confidence and knowledge among police officers is critical, as McDaniel (2018) posits that the lack of procedural clarity in the statutory framework contributes to uncertainty and apprehension among police officers encountering individuals in mental health distress. Mental health training tends to focus on legislation rather than practical, in-depth or scenario-based sessions (Menkes \& Bendelow, 2014), potentially impacting officer confidence in appropriately responding to an individual in distress. These points are reflected in Berry's (2014) survey conducted by the College of Paramedics where paramedic respondents believed the level of understanding of police powers of detainment under the Mental Health Act (1983) among the police to be fairly low.

The introduction of MHST in most localities across England and Wales significantly changes the operational contexts, provisions of support and practices of professionals to respond to people in mental health crisis, and there are very few studies that have provided primary research evidence detailing the operational contexts and practices of professionals. Moreover, current literature is largely focused on service development and providing a rationale for street triage (for example, Horspool et al., (2016), Baraki et al. (2017), Keown et al. (2016) and Reveruzzi \& Pilling, (2016)) and is overly police-centric dominated by a narrative of risk (for example, McDaniel, (2018) and Menkes \& 
Bendelow, (2014)). This paper addresses this gap by considering the interplay between officers and CPNs in practice situated within specific strategic and operational contexts, highlighting shifts in service aims over time, illustrating the influence of place to service developments and revealing the importance of trust in underpinning the interplay between officers and CPNs. Thus, offering original insights in MHST that move beyond current academic discourse in this area.

\section{Method}

\subsection{Study design and setting}

Semi-structured interviews were conducted over a three-month period with individuals in strategic and operational roles in three sites in England where respective police forces and NHS trusts are collaborating to deliver MHST operations. The sites vary in the length of establishment of MHST operations and each implement different operating models. There are, however, similarities in the demographics and geographies served by each model, with each site containing some degree of mix between urban and rural areas. The profile for each site, including operating model, is illustrated in Table 1 (Allen et al., 2018; Home Office, 2017; Home Office, 2018; ONS, 2011).

Insert Table 1 here

\subsection{Materials}

The interview schedule included the following topics: purpose and development of street triage operations; partnership working; practice and decision-making within incidents involving mental health distress; and the future of MHST within the locality. This provided a rich insight into practice and strategic issues whilst being flexible to allow a broader exploration of issues impacting MHST and population mental health within and across the three sites.

\subsection{Recruitment and participants}


14 interviews were conducted across strategic leads within the police, healthcare, and the ambulance service as providers of conveyance to places of safety ( 4 from site 1,7 from site 2 , and 3 from site 3). It should be noted that a number of strategic leads also have operational experience within MHST and some responses reflected this. To compliment the strategic insights, 13 interviews were completed with operational staff within site 2 provided by 5 police response officers, 4 Community Psychiatric Nurses, and 4 Force Control Room Dispatchers. Therefore, the total number of interview analysed was 27 . Comparable data is cited in this article from the strategic leads.

The research team approached potential participants via email, providing participant information sheets detailing how the findings would be used, issues of anonymity, protection from harm and capacity to withdraw from the study (up until finalised data analysis), and all participants provided explicit informed consent prior to taking part. Participants were offered a choice of formats, with some choosing telephone interviews and others choosing face-to-face interviews. Interviews lasted between 30 and 45 minutes and were digitally recorded with the permission of participants. Transcripts were coded by two of the authors independently, who met to agree the themes. The principles of the British Psychological Society Ethical Guidelines (2009) guided ethical practice.

\subsection{Analysis}

Interviews were digitally recorded and transcribed verbatim to enable a rich and reliable interpretation of the data. Transcripts were thematically analysed involving the following six steps: 'familiarisation' through reading and re-reading transcripts, 'code generation', 'theme identification', 'review' of themes and codes, 'labelling themes', and 'report writing' (Braun \& Clarke, 2006).

\subsection{Research ethics}

Ethical approval for the project was obtained from Faculty of Health and Society Research Ethics Committee at the University of Northampton. 


\section{Results}

Four themes were identified in the analysis: 1 . 'Reducing and improving the use of mental health detainments; 2. 'Importance of local contexts and partnerships', 3. 'Enhancing officer confidence'; and 4. 'Developing street triage'.

\subsection{Reducing and Improving the Use of Mental Health Detainments}

The first theme related to reducing and improving the use of mental health detainments by police officers, which links with national reform in terms of recent changes to the Police and Crime Act 2017. The term 's136' was used colloquially by participants when referencing policing detainments under the Mental Health Act (1983), and therefore is used throughout this section. The desire to reduce the use of police powers of mental health detainment was a shared and primary driver in each of the sites. Such a reduction was linked with views of better understanding mental health issues within emergency situations and more appropriately diverting individuals to the support they need.

\footnotetext{
"We still have the original key performance indicators, which were to reduce the number of people inappropriately and unlawfully detained under Section 136 of the Mental Health Act..." (Participant 1 - Site 1 - Health)

"... the project objectives are all about reducing 136s, reducing risks of death in custody, reducing those who go into custody..." (Participant 11 - Site 3 - Police)
}

There was, however, a distinction between the sites in the explicitness of the desire to reduce the use of police powers of detainment among strategic leads. The level of explicitness was related to two entwined factors: professional identity and local context. First, in terms of professional identity, the focus on the need to reduce detainments varied between the police-based partners, who were 
more attentive to reduction, and the health-based partners who were focussed on supporting an individual in crisis to the best possible care. Second, the local context in terms of the proportionate use of powers in terms of being above, in line or below the national average related to directives given to officers on-the-ground, which impacted their decision-making when considering a mental health detainment.

“...sometimes 136 is the right thing to do, sometimes it's not. It's about a better understanding of that rather than the more simplistic view the police had back before we had this access to triage." (Participant 2 - Site 1 - Police)

“...the police had interpreted trying to reduce the number of 136s into they're not allowed to use 136s..." (Participant 6 - Site 2 - Health)

The use of these powers has become a much smaller feature within strategic and operational discourse in sites 1 and 3 , linked to a more established reduction in the usage of detainments alongside robust partnership working practices between the officers and CPNs. The participants in sites 1 and 3 outlined how they were more focused initially on reducing detainments, but, over time, the aims and purpose of MHST had widened to focus more on impacts to the health service, improving the skills and confidence of officers when supporting individuals in crisis within the community and improving service user experience.

“...136s are now a very small part of our role, it's very much more about supporting officers when they go out to live incidents..." (Participant 1 - Site 1 - Health)

“... [after reducing s136s] our commissioners wanted us to think about how do we actually stop people going to ED (emergency department), like prevention of ED admission and attendances..." (Participant 12 - Site 3 - Health) 
Overall, the ambition to improve and reduce the usage of s136 detainments was a shared feature in all sites, though each site was positioned differently within discourse surrounding the purpose and ambition of street triage. As sites 1 and 3 were more mature locales in terms of having been established for a longer period of time and therefore had received greater service development, the evolution of practice on the ground had become more refined, which had moved the focus from reduction to more appropriate use of police powers. A critical facilitator of this development was the inclusion of site 3 within the national programme of street triage pilots, which accelerated progress in terms of practice locally.

\subsection{Importance of Local Contexts and Partnerships}

The second theme identified in the analysis highlighted the importance of local context and partnerships to the strategic and operational functioning of street triage in each site. There was recognition by all that MHST was at the forefront of new purposeful collaborative interagency working between the police and health. Integral to this was the willingness, and ability, of police teams to foster positive relationships with healthcare professionals to improve how the police respond to and make decisions when encountering an individual in crisis. There were several factors involved in how successful these relationships have become, including for example the strength of existing relationships, time allocated to those involved in the programme, previous experience working in partnership, and turnover of officers and staff involved in the programme. Improving the confidence in advice provided by MHST teams to response officers was a priority and focus within each site (discussed further in Theme 3).

"...if they've got to give a Mental Health Act assessment they'll phone me up, I'll check the police systems, we'll mutually decide on risk about whether they need to get a warrant or not." (Participant 3 - Site 1 - Police) 
"...there's a lot of health input gone into the police now, you know, over the last couple of years... ...it's a hundred times better than it was with that sort of joint working." (Participant 7-Site 2-Health)

"[The health trust and the police] have got an excellent working relationship. Much improved. We can pick the phone up and have those conversations rather than it being a battle with a service user in the middle of it." (Participant 12 - Site 3 - Health)

It was acknowledged, when considering demographic and geographic differences between the sites, that the relative investment and resources available to MHST and individuals with poor mental health was impactful to each street triage programme. For instance, the provision and geographic proximity of crisis teams and beds within defined places of safety has created an uneven landscape in which MHST operates. Complicating this further were imbalanced proportions of mental health funding provided to deliver services in each location, affecting levels of localised demand on police and health to respond to people in crisis.

"We were quite lucky in [Site 1] because we sit alongside the crisis team, so we have the facility to directly take patients on for home treatment with the crisis team, which I know nationally a lot of other street triage therapists don't have that." (Participant 1 - Site 1 Health)

"The biggest problem... is getting an approved mental health practitioner out of hours... ...when, somebody comes into the 136, say ten o'clock at night, you know that they're not going to get assessed until at least the next morning and with the 24-hour clock that we've now got, it's going to start making it really tight." (Participant 6 - Site 2 - Health)

Within the sample, there were some strategic leads whose roles crossed geographic policing and health authority boundaries, which enabled differences between the sites to be reflected upon by participants. Such individuals suggested that the decision-making of officers was not consistent, with 
local expectations of practice being different. Moreover, the relative ownership and ability to drive change by operational and strategic leaders was facilitated to different extents across sites, with commissioners suggested to hold unequal levels of commitment to MHST.

"...if you looked at the figures nationally, [Site 2] was a real outlier. I actually think their 136system made it too easy for police officers to use 136 and in turn that affects all of the partners..." (Participant 14-Regional - Health)

"... from a commissioning point of view, I think the commissioners have been more engaged in [Site 1 compared to Site 2] and prepared to back us and support us..." (Participant 14 Regional - Health)

The development of partnerships within sites 1 and 3 has led to shared training between police and health, supported by having established teams of both police and health staff involved in the day-today working of MHST. Shared training was indicated to facilitate joint perspectives and knowledge from which to draw upon when making decisions. This also highlighted a vital role for CPNs in sharing knowledge and skills with officers in a formal training setting to prepare them for a different approach to policing.

"...another strength is that we now do a lot of in-house training for officers on the legislations, on mental health... we run a five-day mental health and decision-making training course..." (Participant 1 - Site 1 - Health)

Within site 3 , it was outlined how partnership was at the centre of strategic and operational development, achieved by holding 'away days' to strengthen respect and cooperation between police and health staff. Considering the historic setup of MHST in site 2, a health professional reflected how the operational change of moving from officers completing overtime to being assigned from general response teams negatively impacted its overall functioning, reputation and effectiveness at supporting individuals to receive the best possible care. 
"...although they were overtime officers, it was a regular batch of officers [in the past], you could do two or three shifts in a week with the same person and they kind of understood why we were doing it and they were motivated to do it." (Participant 5 -Site 2 - Health)

"We had away days so the staff could interact with each other to build that partnership and also it was about gaining respect for both skills..." (Participant 12 - Site 3 - Health)

Overall, the interview data above demonstrate that the structure and strategic management at a local level was critical to the relationships between police and health professionals, and by extension, the perceived effectiveness of each site's street triage operation. Demographic and geographic factors, levels of resource, provisions of mental health services, and support from commissioners were also considered to impact MHST's ability to adequately support individuals in crisis. Here, the relative maturity of street triage programmes was telling, with the more established programmes being perceived as having more robust processes and protocols. Additionally, the evidence presented highlights the importance of identifying key individuals who will remain in post for longer periods of time to achieve continuity and service standards. The way in which police forces choose to deploy officers and strategic leaders to their MHST operations impacts the development of partnerships and effective response practices, with seconded or randomly assigned response officers requiring CPNs to start from scratch with explaining practice and processes, and seconded leaders potentially resulting in a lack of development and strategic 'drift' as the new individuals in post often were learning from limited baseline experience and at time had different ideas and priorities for service development. Also worth noting is that police leaders were responsible for a series of portfolios in addition to mental health, which impacted their focus on this area. Such identified differences highlight the importance of sharing practice and strategy between sites at a regional and national level to advance the development of MHST within locales, embracing new approaches to training, interagency protocols and service development. 


\subsection{Enhancing Officer Confidence}

The third theme related to the level of confidence and trust officers had in the advice provided by health colleagues when responding to an individual in crisis within emergency situations. As noted in the introduction, changes to the Policing and Crime Act 2017 amended the legislative expectation of police officers to consult with a health professional, where practicable, prior to detaining an individual under the Mental Health Act (1983). Whilst the motive for such a move was to improve the appropriate use of the power, it nevertheless relies on officers translating mental health advice from a CPN vis-à-vis their core duties and responsibilities as a police officer, and in most cases trusting advice provided from a CPN concerning their evaluation of risk within pressurised contexts. Concerns about the consequences should the officer leave and an individual harm themselves or take their own life presented the core challenge to be met within MHST.

"...if it's a faceless service, it's really difficult for police officers that are out there dealing with incidents to actually trust what is being said by somebody that is sat in a control room, that actually isn't seeing what the officers are seeing." (Participant 1 - Site 1 - Health)

“...you've got the CPN saying 'this person's not going to harm themselves... ...this is just their normal pattern of behaviour.' And that officer's sitting there, in their own mind thinking 'complaints and discipline, IPCC, losing my job, gross misconduct, lose my pension'. And so it's having the confidence in the CPN." (Participant 8 - Site 2 - Police)

Considering the pivotal importance of trust between police officers and mental health professionals, there was much discussion and focus within sites on how their current model influenced officer confidence and was a consideration within operational and strategic change. Comparing the sites, there were differences in the structure and preferred practices concerning exchanges between police officers and CPNs in terms of control room-based remote exchange of information and a dispatched face-to-face communication, which was in turn was shaped by different levels of 
provision and resource available locally. Important to note was that site 3 previously had both FCRbased provision as well as street triage dispatchable cars in the evening, but when funding was cut, they prioritised the dispatchable part of the service as it was perceived to be more valuable.

“... control room supervisors work in the control room where [the street triage team] work... ...when you're working alongside someone you build that trust.... You can have those discussions face-to-face..." (Participant 9 - Site 2 - Police)

"... what the officers were saying is they feel more confident and I think empowered when street triage physically attend rather than just phone advice because it's always that 'I want you to come and see what I'm seeing and hearing rather than just the phone'." (Participant 13 - Site 3 - Police)

A second aspect of MHST influential to confidence was having dedicated police officers within the triage team - as opposed to randomised officers from a general pool - who were seen as insiders within police and, as such, were trusted as colleagues when conveying advice around decisionmaking. Indeed, officers assessed the communication skills of CPNs to be very high and were impressed by their determination to achieve positive short- and long-term outcomes for individuals in crisis. Whilst lead officers in all sites acknowledged that frontline officers were developing trust in CPN advice, the dedicated officers in sites 1 and 3 had developed a higher degree of confidence in CPNs, an understanding of their expertise as well as how risk was defined within health-based frameworks. An additional result of this more consistent working relationship between officers and CPNs was the development of shared language, specifically the officers coming to understand language and terminologies around mental health services and treatment. Where police leads had been established for longer periods of time, a more established common language had been developed between key staff which enabled better and faster decision-making in practice. As evidenced below, for police leaders, the development of effective communication practices took an extended period of time. 
“...it probably took me a good seven or eight months doing the job full-time, sitting next to a mental health nurse, to understand their world and their lingo and the way they assess risk..." (Participant 3 - Site 1 - Police)

"...to have those dedicated officers for at least six months to two years just so you build up that real experience and dedication and output from them to maximise your results and your reductions in 136s, but also get a real understanding about your repeat callers..." (Participant 11 - Site 3 - Police)

Overall, police officer confidence was a key thread that was impactful to strategic development, in terms of investments, training and structure, and operational practice in terms of decision-making, shared responsibilities and interpretation of risk. Enabling a face-to-face exchange between frontline officers and CPNs was critical to fostering trust and better decision-making on-the-ground by more understanding and knowledge concerning mental health. Having dedicated police officers within street triage teams was identified as facilitating confidence within sites as well as fostering collaboration at the frontier of innovative practice. Moreover, the importance of continuity was evident at developing a common language between CPNs and police leaders, with more established sites having both longer-serving staff and more senior officers in post, which enhanced overall performance.

\subsection{Improving and Developing Street Triage}

The final theme concerned aspirations to improve and develop MHST in all sites. All participants recognised the limitations of the provision in their respective site, often defined in relation to the operational hours of the street triage service. The participants recognised that presentations of people in crisis did not fit neatly into the specific times of the respective MHST service, indicating that people who were in crisis outside of those hours received a poorer response in terms of accessing the support they needed. The desire to expand MHST to '24/7' provision was driven by a 
desire to provide the best possible services for all people, recognising that mental health crises can occur at any time of day. This was, however, perceived as being relatively unrealistic considering the amount of resource and funding within each site.

"...the gold standard, ultimately, would be to have it 24 hours a day, but there is a financial pressure regarding that." (Participant 1 - Site 1 - Health)

"We've aspired for quite a while to have a day car... ...to provide exactly the same service to reduce the 136 detentions during the daylight hours, but unfortunately it is a commissioning issue..." (Participant 12 - Site 3 - Health)

None of the sites had yet adopted a $24 / 7$ model and participants in each were focused on improving and developing the street triage service to be more effective within current provisions. A key part of the service development centred on the actual response to an individual in crisis, organised by having a joint response between agencies as well as those staff having bespoke mental health training to provide appropriate support and make informed decisions. Investing in specialised teams was enabling a cascading of knowledge to flow to wider pools of officers and staff within policing.

"What I would like to do is first respond with an officer, a paramedic and a mental health practitioner. I think that would be, depending on demand, if we could justify it, I think that would be a very good way to deal with it because it ties those agencies together." (Participant 3 - Site 1 - Police)

"... a group of officers that are all trained... and they hold some credence and some kind of oversight of mental health and whatever combined decision-making they make with us is well respected across the force..." (Participant 5 - Site 2 - Health)

There were also several organisational issues being addressed to improve the functioning of MHST. Timely access to health and policing data concerning individuals in crisis to support the response to 
and decision-making for individuals in crisis was a focal area. Here, enabling better access to health systems for the police within the respective control rooms was a priority, though resource, as well as confidentiality and privacy of data, presented barriers. Having dedicated beds for individuals detained under the Mental Health Act (1983) to be assessed was a further issue being negotiated on a daily basis, with the overflow of inpatients compromising their availability.

"... what I would like to see is some facility for the control room to have access to [health systems], either through an administrator or a lower grade nurse..." (Participant 4 - Site 1 Police)

"we should have four Section 136 beds available for officers, if they detain somebody, to take the person to the suites. ...officers sometimes are sat with patients for hours in a family room... So that's a daily challenge, the bed pressures... (Participant 13 -Site 3 - Police)

Overall, the analysis shows that, whilst reported positively, MHST has not yet developed to meet the demand faced by police and healthcare services. Importantly, there was a desire to both expand the service to cover more hours of the day as well as improve the response to individuals in crisis in practice and better utilise current resource to achieve greater impact. Furthermore, there are opportunities to introduce improved information sharing processes, including round-the-clock access to health systems in police control rooms, which would assist police in responding to incidents while CPNs are absent. In this sense, rather than being sceptical or pessimistic concerning MHST, the final theme captured the aspirations of participants, who recognised the value of street triage and wished to develop it further to address a growing level of mental health demand within emergency situations.

\section{Discussion and Implications for Practice}


Despite there being hundreds of mental health triage examples internationally, and thousands of multi-agency 'crisis intervention' type teams, research evidence in this area is limited regarding efficacy of outcomes (Watson et al., 2017). As reflected in this study, this is partly caused by the disparity in models being delivered and by some fundamental differences in perceptions of 'successful' outcomes for service users and the specific roles and responsibilities of the agencies involved (Heyman, 2018). This paper contributes to academic discussion about organisational change, partnership approaches to strategy and policy development, and the implementation of multi-agency responses to problems within society (Heyman, 2018; Cummins \& Edmondson, 2016; Noga et al., 2016). The evidence demonstrates that MHST is considered by key stakeholders to be an effective, valuable and cost-saving model within this context, though effectiveness and cost saving were not measured in this study. However, it is also felt to be under-resourced and underdeveloped, which provides opportunity for improvement in both the scope and scale of delivery. Future research should focus on measuring the effectiveness and cost saving of MHST.

MHST is a prime example of a modern approach to tackling a growing challenge of crisis care emblematic of the vision for the NHS in terms of a place-based system of care (Ham \& Alderwick, 2015). The findings highlight the importance of place in the context of effectively designing and delivering MHST approaches, where each locality has different levels of needs and demand for services, resources across agencies, established relationships between agencies, political and senior practitioner support and commitment, and existing change and transformation programmes, which inevitably impact upon partnership arrangements. Each site's model was found to have a different level of maturity in terms of how long they had been delivering the service and the professionals had formed a shared understanding, position and language, which has a large impact on stakeholder and practitioner understanding of its purpose, organisation and how the MHST model is to be developed moving forward. A point not highlighted elsewhere in literature is how such aims are influenced by professional identity and context, with aims in sites transitioning to a new focus on improving skills and officer confidence to increase resilience in the system. Whilst not discussed in detail in the 
interviews, on reflection there was limited evidence was identified of communication or coordination between the sites to share good practice and learn from each other's experiences and outcomes, with each site iteratively developing in relative isolation, reflecting the broader picture nationally and internationally. There is an existing call in the field for 'contemporary partnerships' to improve the landscape for mental health service provision, which this research adds weight to, demonstrating the need for 'police/health cross-disciplinary education, practice and research' to bring the voices of mental health practitioners and policing genuinely together (Heyman, 2018; Blevins et al., 2014; Watson \& Fulambarker, 2012).

On a practice level, the recent change to the Policing and Crime Act (2017) was interpreted as a positive step forwards in terms of formalising an expectation that police officers will consult with mental health professionals where practicable when supporting an individual in crisis in an emergency. However, the evidence shared in this paper demonstrates that this change alone will not facilitate shared ownership of decision-making and care planning where issues of trust were found to be pervasive between police officers and mental health practitioners. The mode of interaction, for example remote or face-to-face, influenced perceptions of reliability in the advice provided. A new insight not previously identified in literature was the interplay between officers and CPNs, which was informed by perceptions of trust, belonging and legitimacy, shaping notions of confidence, which connects with decision-making in practice and ultimately determined outcomes. This points towards the need to develop bespoke, localised strategies to create the conditions for strengthened relationships and genuine partnership working. Balancing the roles of specialists within omnicompetent teams is one of the key challenges to achieving this, which requires shared understanding of individual and team goals. Reducing the turnover of staff involved, particularly police officers, is vital to creating consistency and building trust.

The expressed benefits of having access to a mental health practitioner highlight the value of health information to the police response to mental health crisis. In particular, access to data was more 
timely, which enabled it to be considered within policing strategies in practice. Moreover, the mental health practitioner was able to explain different mental health conditions and their presentations, translating such knowledge into more informed practice. Mechanisms and strategies to more widely share such information should be explored so that it is not confined to individual exchanges.

The findings suggest that, in addition to practice 'on the ground', inductions and specific training for officers when starting work on MHST units are important in making street triage models effective. Another key gap is the lack of ongoing CPD, which compromises the educational investment in officers and impacts on their confidence in responding to the complexities of mental health presentations. Nurses need to see part of their role within MHST operations as educating and giving practical advice to the officers around them to better deal with individuals in distress. With this in mind, there needs to be a more explicit and informative discussion that outlines the criteria and factors that shape mental health service access decisions. In particular, the thresholds for service access should be shared and explained.

A complicating factor is officer turnover, which is a persistent issue in many areas of police service delivery, relating to both skills development and relationship management both internally and externally. This research adds original insight in this area with findings related to the impact of leadership continuity and staff turnover on MHST efficacy and the potential for strategic 'drift'. The findings also support the wider literature in valuing a model of self-selection for roles in MHST, recognising the importance of personal commitment and self-development to being effective in these partnership roles (Watson et al., 2017).

As outlined in the introduction, there is an ongoing debate concerning whether the police should continue play a key role in meeting the societal demand created by mental health crises. Without taking a stance on this issue, if police are to be involved, data presented in this paper demonstrates the importance of having knowledgeable and sensitive police officers to respond to mental health 
crisis effectively. Considering the inconsistent and localised operations of MHST, the ability of police officers to respond are variable. However, the evidence presented above shows a desire to increase policing resource dedicated to MHST and invest in training and systems to improve confidence, practice and, most importantly, outcomes for individuals in distress.

\section{Conclusion}

This paper provides a qualitative analysis of the perceptions and experiences of key stakeholders and practitioners in the delivery of MHST models in three sites in England, contributing to filling a void in knowledge and evidence on MHST based upon empirical findings. Across the locations MHST is important in improving service provision to individuals in mental health distress in emergency situations. However, it is also under-resourced and in need of further development to facilitate better parity in partnership working practices, shared goals and outcomes across the different localities. Identified throughout the evidence is a call from those involved in street triage work for greater attention on this emerging area to reconceptualise how organisations address demand together and how the sharing of good practice across regions can benefit the locations with less mature operational models. Finally, there is a significant need for more research and evidence to shape and develop MHST models and approaches to enable improved service user experience, better long-term outcomes and increased efficiency across agencies.

\section{References}

Allen, G., \& Jackson, L. (2018). Police Service Strength. House of Commons Library: Briefing Paper. Retrieved from http://researchbriefings.files.parliament.uk/documents/SN00634/SN00634.pdf Baraki, B., Hart, D., Kuyer, J., Pedrick-Case, S., Randles, G., \& Swalem, B. (2017). An evaluation of Hertfordshire Mental Health Street Triage. NEF Consulting: New Economics Foundation. Retrieved 
from http://www.hertscommissioner.org/fluidcms/files/files/Herts-Street-Triage_Final-Report_NEFC-071217.pdf

Berry, M. (2014). College of Paramedics evidence into mental health care and policing. Journal of Paramedic Practice, 6(10), 539-540. Retrieved from http://www.paramedicpractice.com/cgibin/go.pl/library/article.cgi?uid=106213;article=pp_6_10_539_540;format=pdf

Blevins, K. R., Lord, V., \& Bjerregaard, B. (2014). Evaluating crisis intervention teams: Possible impediments and recommendations. Policing: An International Journal of Police Strategies \& Management, 37(3), 484-500. DOI:10.1108/ PIJPSM-08-2012-0083

Bhardwa, S. (2013, September 2). Street triage scheme sees mental health nurses support police. Retrieved from http://www.independentnurse.co.uk/news/street-triage-scheme-sees-mentalhealth-nurses-support-police/63151

Bradley, K. (2009, April 30). The Bradley Report: Lord Bradley's review of people with mental health problems or learning disabilities in the criminal justice system. Retrieved from https://www.basw.co.uk/system/files/resources/basw_120004-10_0.pdf Braun, V., \& Clarke, V. (2006). Using thematic analysis in psychology. Qualitative Research in Psychology, 3(2), 77-101. DOI:10.1191/1478088706qp063oa

Callender, M., \& Cole, S. (2016). Assessing the role, value and effectiveness of mental health triage: Operation Alloy. Institute for Public Safety, Crime and Justice. University of Northampton Charette, Y., Crocker, A. G., \& Billette, I. (2014). Police encounters involving citizens with mental illness: Use of resources and outcomes. Psychiatric Services, 65(4), 511-516.

DOI:10.1176/appi.ps.201300053 
Cummins, I. \& Edmondson, D. (2016). Policing and street triage, The Journal of Adult Protection, 18(1), 40-52, DOI:10.1108/JAP-03-2015-0009

Department of Health. (2009). New Horizons: Towards a shared vision for mental health:

Consultation. Retrieved from http://www.nwcscnsenate.nhs.uk/files/3714/7497/4308/sharedvis.pdf

Department of Health and Concordat signatories. (2014, February 18). Mental Health Crisis Care

Concordat - Improving outcomes for people experiencing mental health crisis. Retrieved from

https://www.crisiscareconcordat.org.uk/wp-

content/uploads/2014/04/36353_Mental_Health_Crisis_accessible.pdf

Engel, R.S. \& Silver, E. (2001). Policing mentally disordered suspects: a re-examination of the criminalization hypothesis. Criminology 39(2), 225-252

Hale, B. (2017). Mental Health Law. $6^{\text {th }}$ Edition. Sweet \& Maxwell: London

Ham, C., \& Alderwick, H. (2015, November 12). Place-based systems of care: A way forward for the NHS in England. Retrieved from

https://www.kingsfund.org.uk/sites/default/files/field/field_publication_file/Place-based-systemsof-care-Kings-Fund-Nov-2015_0.pdf

Heyman, I. (2018) Cross-disciplinary partnerships between police and health services for mental health care. Journal for Psychiatric and Mental Health Nursing, 25(5-6), 283-284.

DOI:10.1111/jpm.12471

HMICFRS. (2018). Policing and Mental Health - Picking Up the Pieces. Her Majesty's Inspectorate of Constabulary and Fire \& Rescue Services. Retrieved from

https://www.justiceinspectorates.gov.uk/hmicfrs/wp-content/uploads/policing-and-mental-healthpicking-up-the-pieces.pdf 
Home Affairs Committee. (2015, February 6). Policing and Mental Health. House of Commons Home Affairs Committee Eleventh Report of Session 2014-15, HC 202. Retrieved from https://publications.parliament.uk/pa/cm201415/cmselect/cmhaff/202/202.pdf Home Affairs Committee. (2018, October 22). Policing for the future. House of Commons Home Affairs Committee Tenth Report of Session 2017-19, HC 515. Retrieved from https://publications.parliament.uk/pa/cm201719/cmselect/cmhaff/515/515.pdf Home Office. (2014). Review of the Operation of Sections 135 and 136 of the Mental Health Act 1983: A literature review. Retrieved from https://assets.publishing.service.gov.uk/government/uploads/system/uploads/attachment_data/file /389254/Literature_Review_S135_and_S136_of_the_Mental_Health_Act_1983.pdf Home Office. (2017). Policing and Crime Act 2017. Retrieved from http://www.legislation.gov.uk/ukpga/2017/3/part/4/chapter/4/enacted Home Office. (2017). Detentions under the Mental Health Act (1983): police powers and procedures year ending 31 March 2017. Retrieved from https://www.gov.uk/government/uploads/system/uploads/attachment_data/file/654469/detention s-mental-health-act-police-powers-procedures-mar17-hosb2017-tables.ods Home Office. (2018). Detentions under the Mental Health Act (1983): police powers and procedures year ending 31 March 2018. Retrieved from https://assets.publishing.service.gov.uk/government/uploads/system/uploads/attachment_data/file /751156/detentions-mental-health-act-police-powers-procedures-mar18-hosb2418-tables.ods Horspool, K., Drabble, S.J., \& O'Cathain, A. (2016). Implementing street triage: a qualitative study of collaboration between police and mental health services. BMC Psychiatry, 16(313), 1-11. DOI:10.1186/s12888-016-1026-z 
Huppert, D., \& Griffiths, M. (2015). Police Mental Health Partnership project: Police Ambulance Crisis Emergency Response (PACER) model development. Australasian Psychiatry, 23(5), 520-523.

DOI:10.1177/1039856215597533

Lamb, R.L., Weinberger, L.E., \& DeCuir Jr, W.J. (2002). The police and mental health. Psychiatric Services, 53(10), 1266-1271. DOI:10.1176/appi.ps.53.10.1266.

Livingston, J. (2016). Contact between police and people with mental disorders: A review of rates. Psychiatric Services, 67(8), 850-857. DOI:10.1176/appi.ps.201500312

Kane, E., Evans E., \& Shokraneh, F. (2017). Effectiveness of current policing-related mental health interventions in England and Wales and Crisis Intervention Teams as a future potential model: a systematic review. Systematic Reviews, 6(85), 1-7. DOI:10.1186/s13643-017-0478-7

Keown, P., French, J., Gibson, G., Newton, E., Cull, S., Brown, P., Parry, J., Lyons, D., \& McKinnon, I. (2016). Too much detention? Street Triage and detentions under Section 136 Mental Health Act in the North-East of England: a descriptive study of the effects of a Street Triage intervention. BMJ Open, 6, 1-8. DOI:10.1136/bmjopen-2016-011837

McDaniel, J.L.M. (2018). Reconciling mental health, public policing and police accountability. The Police Journal: Theory, Practice and Principles, 1-23. DOI:10.1177/0032258X18766372

Menkes, D.B., \& Bendelow, G.A. (2014). Diagnosing vulnerability and "dangerousness": police use of Section 136 in England and Wales. Journal of Public Mental Health, 13(2), 70-82. DOI:10.1108/JPMH09-2012-0001

Ministry of Justice. (2011). MoJ Equalities: Annual Review 2010-2011. Retrieved from http://www.justice.gov.uk/downloads/publications/corporate-reports/MoJ/2011/equalities-annualreview-2010-2011.pdf 
Noga, H., Foreman, A., Walsh, E., Shaw, J., \& Senior, J. (2016). Multi-agency action learning:

Challenging institutional barriers in policing and mental health services. Action Research, 14(2), 132150. DOI:10.1177/1476750315583315

O'Brien, A., Sethi, F., Smith, M., \& Bartlett, A. (2017). Public mental health crisis management and Section 136 of the Mental Health Act. Journal of Medical Ethics, 44(5), 349-353.

DOI:10.1136/medethics-2016-103994

Office for National Statistics. (2011). Local Area Report for Areas in England and Wales. Retrieved from https://www.nomisweb.co.uk/reports/localarea [Accessed on 2 July 2019]

Pettitt, B., Greenhead, S., Khalifeh, H., Drennan, V., Hart, T., Hogg, J., Borschmann, R., Mamo, E., \& Moran, P. (2013). At risk, yet dismissed: the criminal victimisation of people with mental health problems. Retrieved from: https://www.mind.org.uk/media/642011/At-risk-yet-dismissedreport.pdf

Reveruzzi, B., \& Pilling, S. (2016). Report on the evaluation of nine pilot schemes in England. Retrieved from https://www.ucl.ac.uk/pals/sites/pals/files/street_triage_evaluation_final_report.pdf The British Psychological Society. (2009). Code of Ethics and Conduct Guidance published by the Ethics Committee of the British Psychological Society. Retrieved from https://www.bps.org.uk/sites/bps.org.uk/files/Policy/Policy\%20\%20Files/Code\%20of\%20Ethics\%20and\%20Conduct\%20(2009).pdf Watson, A.C., Compton, M.T., \& Draine, J.N. (2017) The crisis intervention team (CIT) model: An evidence-based policing practice? Behavioural Sciences and the Law, 35(5-6), 431-441. DOI:10.1002/bsl.2304 
Watson, A., \& Fulambarker, A. (2012). The crisis intervention team model of police response to mental health crises: A primer for mental health practitioners. Best Practices in Mental Health, 8(2), $71-81$.

White, C., \& Weisburd, D. (2017). A co-responder model for policing mental health problems at crime hot spots: Findings from a pilot project. Policing: A Journal of Policy and Practice, 12(2), 194209. DOI:10.1093/police/pax059

Winsor, T.P. (2017). State of Policing - The Annual Assessment of Policing in England and Wales 2016. Her Majesty's Chief Inspector of Constabulary. Her Majesty's Inspectorate of Constabulary. Retrieved from https://www.justiceinspectorates.gov.uk/hmicfrs/wp-content/uploads/state-ofpolicing-2016-double-page.pdf

Wood, J., Swanson, J., Burris, J.D., \& Gilbert, A. (2011, March 9). Police interventions with persons affected by mental illnesses: A critical review of global thinking and practice. SSRN. Retrieved from https://papers.ssrn.com/sol3/papers.cfm?abstract_id=1781909 